\title{
Bielova O. B. Features of speech development in children with autistic spectrum disorders
}

In scientific work, the theoretical analysis on the problem of studying the indicators of speech development in children with autism spectrum disorders. The purpose of the study is a theoretical study of features of speech development in children with autistic spectrum disorders. Objectives of the study: to highlight the theoretical analysis of the scientific literature, both classical and modern research, on the problem of study; consider the causes of autism, the causes of speech disorders, and features of speech development for children autistic disorders; described species according to the International Classification of Diseases. As a result of scientific and theoretical research it was determined that depending on the specifics of disorders and the degree of lesions of the cerebral cortex, speech development in children with autism spectrum disorders have its own characteristics; the variability of speech development is determined; revealed a different levels of development of speech depending on the type of autism. The study described different groups of children with autism spectrum in the determine development of their active speech. Children in the first group have speech disorders due to mental retardation. Speech disorders in children of the second group are characterized by a delay in the organization of consciousness. In children of the third group, speech disorders of catatonic symptoms were observed. Speech disorders due to mental regression are observed in the fourth group. Speech disorders in the fifth group of children are associated with the pathology of the associative process. Delay in speech development, depleted vocabulary, unclear, meaningless, limited speech, the presence of echolalia, agrammatism, lack of motivation to communicate, communicative deprivation, requires a special training and correction approach.

Key words: children with autism spectrum disorders, speech, speech disorders.

УДК 339.13:796.4:614.46

DOI https://doi.org/10.31392/NPU-nc.series5.2021.81.07

Бистра І. І., Чайченко Н. Л., Клименко Г. В., Ковальова А. О.

\section{АНАЛІЗ РИНКУ ФІТНЕС-ПОСЛУГ В ОЗДОРОВЧО-СПОРТИВНІЙ СФЕРІ В УМОВАХ КАРАНТИНУ}

Державна підтримка розвитку сфери фізкультурно-спортивних послуг має велике політичне та соиіальне значення. Інтенсивний розвиток спортивного руху безпосередньо пов'язаний зі зміцненням здоров'я громадян. Активний інтерес населення до спорту полягає в організації процесу тренувань, розвитку та вдосконалення сил $i$ можливостей людини, а саме: фізичних, емоиійних, адаптаційних, духовних. Фітнес-індустрія розглядається як сфера послуг, сукупність різних суб'єктів фітнес-діяльності. У статті проаналізовано всі обмеження та правила роботи фітнесценттів в умовах карантину та розллянуто проблеми і моніторинг сучасних фітнес-клубів. За оцінками експертів, у більшості мережевих клубів добре представлено тренажерні зали та групові заняття, однак кількість басейнів не покриває споживчих запитів.

Провівши аналіз, можна довести, що ия специффіка спортивних клубів є безпечною та повністю відповідає санітарним нормам. Вивчення аналізу ринку фітнес-послуг в оздоровчо-спортивній сфері в умовах карантину доводить, щчо споживачі не готові до повного переходу на дистанційну форму занять із тренерами. Респонденти визначають, щчо ідеальний фітнес-клуб - ие такий, в якому враховують такі фактори: індивідуальні можливості та рівень фізичної підготовки, альтернативні онлайн-програми, створення комфортних умов для занять і тренувань. Ключовою особливістю брендових мережевих клубів є надання комплексу всіх можливих оздоровчо-спортивних послуг в одному клубі.

Незважаючи на те, щзо мережі сильно розиирилися завдяки відкриттю нових клубів, поодинокі клуби також активно відкриваються та врівноважують картину, де в повному обсязі представлено тренажерні зали та групові заняття. С хиби в иььому напрямі: споживачі не готові до повного переходу на дистаниійну форму занять із тренерами, а також закриття спортивних клубів. Усе це негативно вплинуло на комерціалізацію фітнес-клубів. В умовах карантину спортивна сфера зазнала значних втрат.

Ключові слова: здоровий спосіб життя, оздоровчо-спортивна сфера, пандемія, фітнес, фітнес-клуби, фітнеспослуги.

Нині активно спостерігається заохочення споживачів до оздоровчих та спортивно-оздоровчих послуг у фітнес клубах. Активний інтерес населення до спорту полягає в організації процесу тренувань, розвитку сил і можливостей людини, а саме - фізичних, емоційних, адаптаційних, духовних. Фітнес-індустрія розглядається як сфера послуг, сукупність різних суб'єктів фітнес-діяльності (фітнес-клуби, фітнес-центри, спортивні клуби, студії, спортивно-оздоровчі центри, оздоровчі центри, тренажерні зали), що надають фітнес-послуги, із залученням до здорового способу життя, підтримки, збереження та зміцнення здоров'я людини, а також досягнення високих результатів із корекції фігури. Останніми роками попит на користування спортивно-оздоровчими та фітнес-послугами дедалі більше зростає $[1 ; 2]$.

На жаль, погіршилася ситуація з відвідуванням фітнес-центрів під час карантину. Нині в Україні складна епідеміологічна ситуація. Триває загальнонаціональний карантин через поширення вірусу COVID-19. Oбмежено авіаційне та залізничне сполучення з іншими країнами, компанії та заклади перейшли на віддалену роботу, людей закликають не виходити з дому без потреби, обмежено масові заходи. Постає питання: як саме це вплинуло на роботу фітнес-центрів? [3]. 
Пандемія COVID 19 значно змінила повсякденне життя кожної людини. Адже такі звичні колись речі, як похід у басейн і спортзал, стали майже не можливими. Сьогодні це одне 3 найбільш популярних місць дозвілля людей різних вікових категорій. Здоровий спосіб життя в сучасному світі нині в тренді. На період адаптивного карантину було розроблено вимоги та правила, які дали можливість не припиняти тренування та тримати себе у формі.

Якщо чітко дотримуватися всіх настанов, що розробили провідні епідеміологи, то можна тренуватися, не наражаючи себе та оточення на небезпеку. Зміни зачепили й роботу фітнес-центрів.

У цьому випадку розглянуто надання оздоровчо-спортивних послуг під час пандемії у брендових мережевих фітнес-клубах і відокремлених маленьких фітнес-студіях у місті Києві. Така стратегія передбачає комплексний моніторинг ринку в екстремальній ситуації в період карантину. Було вивчено використання багатьох методик покращення та підтримки здоров'я, гарного самопочуття, реалізації принципів якісного життя, а саме: дієтологія, використання різних фітнес-програм, психологічної релаксації, гармонізації, комфортних фізичних навантажень, включно зі спортивно-оздоровчими заняттями, доглядом за тілом і зовнішністю, інших форм оздоровлення [4; 5].

Проблемам надання послуг у сфері фітнесу присвячено низку наукових праць М. М. Булатової, І. Л. Гасюк, С. В. Бірючинської, К. Ю. Литвинової, М. Е. Кутепова та інших. Також проблеми розвитку фітнес-індустрії знайшли своє зображення в дослідженнях Ю. П. Мічуди й А. В. Ольшевського.

Проте методологічні та практичні аспекти, які формують ситуацію сьогодення у вітчизняних фітнес-клубах під час карантину, та надання фітнес-послуг споживачам потребують подальшого вивчення.

До активного моніторингу підлягає сегмент брендових мережевих фітнес-клубів через велику кількість відвідувачів. Збільшення попиту на фітнес-послуги дає змогу порівняти прибутковість та якість послуг. Авторами було проведено аналіз ринку фітнес-послуг в оздоровчо-спортивній сфері клубів у м. Києві. Також досліджено якість надання фітнес-послуг мережі фітнес-центрів середнього цінового сегмента (фітнесстудій у місті Києві: “Sportstudio”, “Формула тіла” та “Фактура”) та брендових фітнес-клубів (“FitCurves”, "SportLife”, “Спортленд”).

Головний державний санітарний лікар України своєю постановою від 2 червня 2020 р. №33 дав рекомендації для тимчасової організації протиепідемічних заходів у закладах фізичної культури і спорту на період карантину через поширення коронавірусу (COVID-19) [7].

Загальні вимоги: на початку занять проводити температурний скринінг усім працівникам і відвідувачам закладів; особи, температура тіла яких була понад $37,2^{\circ} \mathrm{C}$ або мали ознаки респіраторних захворювань, не допускались до роботи та тренувань.

Одночасно у приміщенні не дозволяється перебування більш ніж однієї особи на 10 м² площі зали для індивідуальних занять і не більш однієї особи на 5 м² площі зали для групових/командних занять (максимум 10 людей у групі). Проведення таких занять дозволено виключно за попереднім записом. На вході до фітнес-центру повинно бути місце для обробки рук спиртовмісними антисептиками з концентрацією активної речовини понад 60\% для ізопропілових спиртів і понад 70\% для етилових спиртів.

Рекомендовано встановити яскраву вказівку про необхідність дезінфекції рук (плакат, наклейка та ін.). У зонах проведення занять - облаштувати додаткові місця для оброблення рук антисептиками, паперові рушники, закриті урни для їх утилізації. Розмістити дошку з нагадуванням для клієнтів про необхідність дотримання гігієни, дезінфекції рук і спортивного інвентарю після тренування. Обмежити одночасне користування роздягальнями та душовими кабінами (не більш як 50\%), закрити кожну другу шафу для роздягання/душову кабіну та нанести відповідні позначки, щоб унеможливити контакти між клієнтами. Кількість людей, що перебувають у центрі, не повинна допускати скупчення їх у роздягальнях, санітарних кімнатах та адмінзонах. Тренажери, призначені для кардіотренувань, що мають довгий цикл користування однією людиною, повинні бути розташовані не менше як за 2,5 метра один від одного [3].

Забороняється використовувати багаторазові рушники (окрім особистих рушників клієнтів): доступ відвідувачів до рекламних листівок, журналів та газет; робота SPA-зон і послуги масажу; дія фітнес-барів і кулерів із водою; функціонування дитячих кімнат; користування багатофункціональними тренажерами декількома відвідувачами одночасно; проведення занять групами, де є більш ніж десять осіб, та інших занять, що передбачають безпосередній фізичний контакт.

Вимоги до працівників і роботодавців фітнес-центрів: працівники повинні бути в масках або респіраторах; після кожного заняття міняти маску та обробляти антисептиком чи мити руки; адміністрація закладу повинна забезпечити своїх працівників запасом масок та антисептиків щонайменше на п'ять днів та організувати утилізацію використаних індивідуальних засобів; забезпечити наявність рідкого мила та паперових рушників у санвузлах, дезінфікувати поверхні що дві години, провітрювати приміщення, та робити вологе прибирання з дезінфекційними засобами якомога частіше [7].

Метою статті $\epsilon$ вивчення ринку фітнес-послуг в оздоровчо-спортивній сфері в умовах карантину.

Для досягнення мети було використано такі методи дослідження: аналіз даних науково-методичної літератури та необхідних інтернет-ресурсів; анкетування (опитування) клієнтської бази клубів, участь у якому взяли 130 респондентів, з яких 36\% становили чоловіки та 64\% - жінки. 
Структура розподілу фітнес-клубів за ознакою мережевий/немережевий порівняно за період із 3 грудня 2020 р. до 18 березня 2021 р. Незважаючи на те, що мережі значно розширилися завдяки відкриттю нових клубів, поодинокі клуби також активно набирають обертів і зрівноважують картину. За оцінками експертів, у більшості мережевих клубів досить представлено тренажерні зали та групові заняття, однак кількість басейнів не покриває споживчих запитів. Ключовою особливістю SportLife є надання комплексу всіх можливих оздоровчо-спортивних послуг в одному клубі. У кожному фітнес-клубі є тренажерний зал, студії групових програм, басейни (спортивний, дитячий, для немовлят), дитячий фітнес, сквош-корти, боксерські ринги та лаунж-зони. SportLife - це також найбільша мережа банних комплексів в Україні, яка включає SPA-програми, пілінг тіла, скраби, мильні масажі, водні процедури обгортання - усе це під одним дахом. FitCurves - міжнародна франшиза і лідер у сфері фітнес-послуг для жінок, це найбільш швидкозростаюча франчайзингова мережа в світі за версією Книги рекордів Гіннеса. За 10 років понад 120 підприємців в Україні відкрили свої клуби та окупили початкові інвестиції в період 6-18 місяців завдяки системній підтримці фахівців компанії та програмі оперативного управління “Кайдзен”.

Натомість, невеликі та немережеві фітнес-студії “Sport studio”, “Формула тіла” та “Фактура” набувають сили та обертів завдяки індивідуальному підходу до клієнтів і споживачів фітнес-послуг, раціональному ціноутворенню та компетентному тренерському складу. За даними опитування споживачів фітнес-послуг, на жаль, на першому місці стоїть вартість послуг, а також їхня доступність. Менш вагомим споживачі вважають асортимент послуг. І хоча професіоналізм тренерського складу досі не посідає лідерських позицій, кількість опитаних, які надали значення цьому параметру, зростає. Отже, з'ясувалося, що зі збільшенням кількості клубів та популярності фітнесу в м. Києві споживач буде більш вимогливим до якості фітнес-послуг. Фітнестренди, які набувають популярності: високоінтенсивні інтервальні тренування; групові програми в маленьких групах; персональний та індивідуальний тренінг; вправи з вагою власного тіла; силовий тренінг; йога; тренування на свіжому повітрі; функціональний фітнес.

Актуальними напрямами за період дослідження респонденти вважають: вправи для зниження ваги, функціональний тренінг, персональні тренування в мінігрупах (2-4 людини), тренування на відкритому повітрі; міофасціальний реліз для поліпшення гнучкості та рухливості м'язів; коловий тренінг; кросфіт; спортивні тренування (змагання).

Цікавими були причини, через які клієнти не бажають користуватися додатковими послугами в оздоровчо-спортивному закладі: активне поширення онлайн-занять, не виходячи 3 дому $(33,7 \%)$; немає послуг, які були б до вподоби (41,3\%); вистачає занять фізичними вправами на відкритому повітрі (24\%); відсутність бажання (2,1\%). Під час анкетування респонденти зазначили, що ідеальний фітнес-клуб - це такий, у якому враховують такі фактори: індивідуальні можливості та рівень фізичної підготовки (16,7\%); пропонують альтернативні онлайн-програми, у разі якщо особа не встигає за всіма або в неї зовсім не виходить (10, 3\%); працівники докладають максимальних зусиль, щоби створити комфортні умови для занять фізичними вправами й оздоровлення (27,4\%); фахівці постійно вдосконалюються (відвідують семінари, конференції, курси), для того щоб заняття завжди були цікавими (35,5\%); можна після занять фітнесом відпочити, відновитись і покинути заклад у прекрасному самопочутті (10,1\%). Із перелічених відвідувачами послуг, якими вони користуються у фітнес-клубах, центрах, студіях, на першому місці відвідування тренажерної зали (42,0\%). На другому - групові направлення (20,3\%). Має попит відвідування басейнів (18,7\%). Після занять фітнесом відвідують сауну - 14,3\% респондентів, а порадами дієтолога користуються - 2,7\%. Частка досліджуваних, які, окрім фітнес-послуг, користуються ще й додатковими "Spa" i "Wellness" послугами та яким до вподоби їхня якість, становить $61,4 \%$, i, відповідно, не задоволені - 38,2\% клієнтів. Цікавими були причини, через які клієнти не бажають користуватися додатковими послугами в оздоровчому закладі. Респонденти пояснюють це так: на це не вистачає коштів $(33,7 \%)$; немає послуг, які були б до вподоби $(41,3 \%)$; вистачає занять фізичними вправами (24\%); відсутність бажання $(2,1 \%)$.

Висновки. Отже, проаналізувавши всі обмеження та правила роботи фітнес-центрів в умовах карантину, можна довести, що ця специфіка спортивних клубів є безпечною й повністю відповідає санітарним нормам. Вивчення аналізу ринку фітнес-послуг в оздоровчо-спортивній сфері в період пандемії доводить, що споживачі не готові до повного переходу на дистанційну форму занять із тренерами. Респонденти визначають, що ідеальний фітнес-клуб - це такий, у якому враховують такі фактори: індивідуальні можливості та рівень фізичної підготовки, пропонують альтернативні онлайн-програми, працівники докладають максимальних зусиль, щоби створити комфортні умови для занять і тренувань. Перспективи подальших досліджень будуть спрямовані на пошук нових видів ринку фітнес-послуг в оздоровчо-спортивній сфері в умовах карантину.

Використана література:

1. Благій О. В., Лисакова Н. О. Тенденції розвитку групових фітнес-програм. Теорія $i$ методика фізичного виховання $i$ спорту. 2013. № 2. С. 54-58.

2. Ващук Л. М. Передумови розвитку та становлення фітнесу в Україні. Physical education, sports and health culture in modern society. 2013. № 3 (23). С. 7-9.

3. Вимоги до робот фітнес центрів. URL: https://news.dtkt.ua/labor/labor-relations/62920 (дата звернення: 12.02.2021).

4. Кандаурова Н. В., Лобанов Н. А. Підприємницька діяльність і особливості маркетингу фізичної культури і спорту. Вченi записки університету. Санкт-Петербург, 2013. № 11 (105). С. 28-31. 
5. Леонов Я. В., Приходько И. И., Путятина Г. Н. Внутренний ресурс развития сферы физической культуры и спорта в новой экономике Украины. Теория и практика физической культуры. 2013. № 3. С. 65-67.

6. Обов'язкові умови фітнес центрів на карантині. URL: https://wz.lviv.ua/article/411502-vykhid-z-karantynu-fitnes-tsentryi-kinoteatry-treba-vidkryvaty-odnymy-z ostannikh. URL:https://sud.ua/ru/news/ukraine/169047-yak-pratsyuvatimut-sportzalipid-chas-karantinu-nazvali-obovyazkovi-umovi (дата звернення: 07.04.2021).

7. Правила роботи фітнес-центрів на карантині. URL: https://covid.unian.ua/poslablennya-karantinu-pravila-roboti-baseynivsportzaliv-y-fitnes-centriv-11018555.html (дата звернення: 20.01.2021).

8. Русинович С. В. Обзор рынка фитнес услуг Украины. Дело. 2018. № 32. С. 86-90.

9. Чеховська Л. М. Характеристика діяльності мережі фітнес-клубів "FITCURVES". Спортивна наука України. 2018. № 2 (84). C. 48-54.

\section{References:}

1. Blaghij O. V., Lysakova N. O. (2013) Tendenciji rozvytku ghrupovykh fitnes-proghram. [Trends in the development of group fitness programs] Teorija i metodyka fizychnogho vykhovannja i sportu. 2013. \# 2. S. 54-58.

2. Vashhuk L. M. (2013) Peredumovy rozvytku ta stanovlennja fitnesu v Ukrajini. [Prereguisites for the development and formation of fitness in Ukraine] Physical education, sports and health culture in modern society. 2013. (23). S. 7-9.

3. Vymoghy do robot fitnes centriv. [Regusrements for robot fitness centers]. URL: https://news.dtkt.ua/labor/labor-relations/62920. (data zvernennja 12.02.2021). [in Ukrainian].

4. Kandaurova N. V., Lobanov N. A. (2013) Predprynymateljskaja dejateljnostj y osobennosty marketyngha fyzycheskoj kuljtury y sporta. [Entrepreneurial activity and features of marketing of physical culture and sports] Uchenye zapysky unyversyteta. S-P. 2013. \# 11 (105). S. 28-31.

5. Leonov Ya. V., Prihodko I. I., Putyatina G. N. Vnutrenniy resurs razvitiya sferyi fizicheskoy kulturyi i sporta v novoy ekonomike Ukrainyi. Teoriya i praktika fizicheskoy kulturyi. 2013. \# 3. S. 65-67.

6. Obov'jazkovi umovy fitnes centry na karantyni. [Quarantine fitness centers are required]. URL:https://wz.lviv.ua/article/411502-vykhid-z-karantynu-fitnes-tsentry-i-kinoteatry-treba-vidkryvaty-odnymy-zostannikh. URL:https://sud.ua/ru/news/ ukraine/169047-yak-pratsyuvatimut-sportzali-pid-chas-karantinu-nazvali-obovyazkovi-umovi. (data zvernennja 07.04.2021). [in Ukrainian].

7. Pravyla roboty fitnes centriv na karantyni. [Rules of operation of fitness centers in guarantine]. URL: https://covid.unian.ua/ poslablennya-karantinu-pravila-roboti-baseyniv-sportzaliv-y-fitnes-centriv-11018555.html. (data zvernennja 20.01.2021). [in Ukrainian].

8. Rusinovich S. V. Obzor ryinka fitnes uslug Ukrainyi. Delo. 2018. \# 32. S. 86-90.

9. Chekhovsjka L. M. (2018) Kharakterystyka dijaljnosti merezhi fitnes-klubiv "FITCURVES". [Characteristics of the network of fitness clubs "FITCURVES"] Sportyvna nauka Ukrajiny. \# 2 (84). S. 48-54.

Bustra I. I., Chaichenko N. L., Klumenko G. V., Kovalova A. O. Analysis of the market of fitness services in the health and sports sphere in quarantine conditions

State support for the development of physical culture and sports services have a political and social importance. Intensive development of sports movement is directly related to strengthening the health of citizens. The active interest of the population in sports is to organize the process of training, development and improvement of human strengths and abilities, namely physical, emotional, adaptive, spiritual.The fitness industry is considered as a sphere of services, a set of different subjects of fitness activity. In the article analyzes all the restrictions and rules of fitness centers in quarantine and considered the problems and monitoring of modern fitness clubs. According to experts, most network clubs has well-represented gyms and group classes, but the number of pools does not cover consumer demands. After analyzing all the restrictions and rules of fitness centers in quarantine, we can prove that this specificity of sports clubs is safe and fully in compliance with sanitary norms. A study of the analysis of the market of fitness services in the field of health and sports in quarantine conditions proves that consumers are not ready for a full transition to a remote form of training with coaches. Respondents determine that the ideal fitness club, which is one that takes into, accounts the following factors: individual possibilities and level of physical training, offer alternative online programs, employees make every effort to create comfortable conditions for classes and training. A key feature of brand network clubs is the provision of a range of all possible sports and wellness services in one club. Despite the fact that, the networks have greatly expanded due to the opening of new clubs, individual clubs are also actively opening and balancing the picture, where gyms and group classes are well represented. There are shortcomings in this area, where consumers are not ready for a full transition to a remote form of training with coaches and the closing of sports clubs - all this has negatively affected the commercialization of fitness clubs. In quarantine, the sports sector suffered significant losses.

Key words: healthy lifestyle, health and sports, pandemic, fitness, fitness clubs, fitness services. 